\title{
PhD Thesis Writing Process: A Systematic Approach-How to Write Your Literature Review
}

\author{
Qais Faryadi \\ Future Expert Solutions, Creative Research and Innovations, Kuala Lumpur, Malaysia \\ Email: user@magnesium4you.com
}

How to cite this paper: Faryadi, Q. (2018). PhD Thesis Writing Process: A Systematic Approach-How to Write Your Literature Review. Creative Education, 9, 2912-2919. https://doi.org/10.4236/ce.2018.916219

Received: November 21, 2018 Accepted: December 25, 2018

Published: December 28, 2018

Copyright $\odot 2018$ by author and Scientific Research Publishing Inc. This work is licensed under the Creative Commons Attribution International License (CC BY 4.0).

http://creativecommons.org/licenses/by/4.0/

\begin{abstract}
Literature writing is a skill that every $\mathrm{PhD}$ candidate must procure to communicate his or her research findings clearly. The main objective of this paper is to facilitate the literature writing process so that $\mathrm{PhD}$ candidates understand what $\mathrm{PhD}$ literature is and are able to write their $\mathrm{PhD}$ literature correctly and scientifically. The methodology used in this research is a descriptive method as it deliberates and defines the various parts of literature writing process and elucidates the how to do of it in a very unpretentious and understanding language. As thus, this paper summarizes the various steps of literature writing to pilot the $\mathrm{PhD}$ students so that the task of $\mathrm{PhD}$ literature writing process becomes adaptable and less discouraging. This research is a useful roadmap especially for students of the social science studies. Additionally, in this paper, literature writing techniques, procedures and important strategies are enlightened in a simple manner. This paper adopts a how-to approach when discussing a variety of relevant topics, such as literature review introduction, types of literature review, advantages of literature reviews, objective of literature review, literature review template, and important check lists about literature review are discussed. This paper has 5 parts, such as Introduction, Literature Review, Methodology, Results and Conclusion. The literature review chapter is discussed in this paper. I will discuss the rest as a series in the future.
\end{abstract}

\section{Keywords}

Thesis Writing Process, Literature Review, PhD, Social Science, Research Methodology

\section{Introduction}

Review of literature is the second stage in the thesis writing process. It is a criti- 
cal appraisal of published literature by qualified and accredited scholars and researchers in the field of your study. When you cite certain researchers, you are saying that your research is related to their findings in certain aspects (Badenhorst, 2018). The selected research papers should be current, and they should strengthen your argument about your research topic. They should help to outline the objectives, goals and purpose of your research.

The literature review is not a merely summary of whatever articles you have read, nor is it a long bibliographic annotation. It is also not simply a list of studies that have been done and published on your research topic. You need to critically appraise related studies by scholars in the field to show whether they support your problem statement. You must have the skills to seek the necessary information in the literature to provide the theoretical framework and methodology for your study so that you create new knowledge when you publish your work (Dena, 2013).

How do you defend your claims? Once you establish a relationship between your claims and related findings and theories from the literature, you will have a theoretical framework to lend support to your investigation (Galvan \& Galvan, 2017). The word review consists of two parts, re and view. This means that you need to revisit existing work to find answers, to view new knowledge or the latest findings related to the topic. Literature search is considered a secondary source of information and lacks experimental value.

A good literature search must reflect scholarly evaluation of findings by other scholars who have investigated areas related to your topic and research problem. According to Dr. Neelima Mehta, "a review of the literature is a written summary of journal articles, books and other documents that describes the past and current state of information, organizes the literature into topics and documents a need for a proposed study." (Qais, 2017: p. 34).

"A literature review is an objective, critical summary of published research literature relevant to a topic under consideration for research. Its purpose is to create familiarity with current thinking and research on a topic and may justify future research into a previously overlooked or understudied area" (Thompson Rivers University-@ Pamela Fry).

According to the Merriam Webster Dictionary, literature refers to literary work of a scholarly nature. Conducting a literature review helps you to clarify the theoretical and conceptual issues that are related to your work so that you can formulate your research design correctly.

Apart from that, literature review gives you an opportunity to persuade your readers that your research topic is worthy of further investigation. Moreover, a good literature review strengthens your claims and gives you the chance to create new knowledge in support of other researchers, or even to disprove some of their findings.

According Creswell (2005), the following are some important techniques of doing literature search:

1) Categorize the keywords of your topic and search in scholarly databases 
online. Start with general keywords and slowly narrow down your search. Identify main concepts and theories that are relevant to your research problem and hypotheses.

2) Identify your research purpose, objectives, nature of your study, type of problem and research questions so that you can concentrate on relevant studies.

3) Utilize academic libraries, electronic sources, primary and secondary sources. Focus mainly on primary sources (original work, first-hand account of events and literature, including diaries, creative works, letters, newspaper articles, reports, photographs, financial records, memos, etc.).

4) When you select literature to review, make sure you review it critically. Consider every angle of an issue. Pay attention to who argues for or against your claims. Look for strengths, weaknesses and limitations of their studies.

5) Your search should also include refereed academic journals, conference proceedings, theses and dissertations as such literatures usually contain current qualitative and quantitative research findings. When citing opinions, make it clear that they are opinions and not substantiated facts. Limit your citation of websites. Websites lack academic standing.

6) It is also crucial to have good organization of the literature that you intend to read and those that you have read. When you do a literature review, you need to read hundreds of papers that are relevant to your topic. Hence, you must organize them properly so that you remember who said what. One of the best organization methods for your reviewed literature is to create a folder in your computer. In that folder arrange all your reviewed articles accordingly. There should be proper indexing and referencing to facilitate writing the reference section of your thesis.

7) One of the best referencing styles in thesis writing is the American Psychological Association (APA) style (which will be discussed later).

8) When doing a literature review, read the abstract of the article first. Generally, there is no need to read the rest of the paper unless critical issues are discussed in other sections. Look for the results and conclusion of that article in the abstract. While reading scholarly articles, look for the gap in the knowledge and see whether there is any direct relationship to your investigation. As part of your literature review, have a habit of taking short notes from the field and interviews (Rewhorn, 2018).

9) If you cannot find articles in support of your claims, never state that nothing has been written about your research topic. Perhaps you have not carried out adequate investigation. Maybe the topic is discussed in detail in other languages, but you are not aware of it. So, you could just say: To the best of my knowledge, no study has been conducted on ... Nevertheless, try your best to find materials to support your research questions, hypothesis and your problem statement. Make sure you acknowledge the source of your information.

10) Not all written literatures are scholarly. You must ask yourself about the authenticity of the article. Does the article clarify your topic? What are its limitations? Does this article help you to answer your questions? Has the author ana- 
lyzed the findings correctly or objectively? What is his/her contribution?

When writing your review of literature, you must show your readers what information has been documented about your problem statement and what knowledge has not been documented yet so that your findings might narrow or fill the gap in the literature. Your literature review should showcase studies that are related to your research objectives, questions and problem statement. The articles you cite should define and strengthen your case for an in-depth investigation of the research problem (Price, 2017).

As mentioned earlier, your literature review should not be just a long list of bibliographic references or a summary of re-articulated materials.

\section{Problem Statement}

Writing literature reviews require exceptional skill that every $\mathrm{PhD}$ candidate must take note in order to convey his or her research findings clearly. Unfortunately, majority of $\mathrm{PhD}$ candidates find it difficult to finish their thesis on time because of confusion and lake of expertise in writing literature review. Most of them in deed do not know how to write the literature review correctly, scientifically and how to cite them properly.

\section{Objectives}

1) To assist PhD candidates to understand what literature review means.

2) To describe literature review writing process.

3) To help $\mathrm{PhD}$ candidates in writing literature review academically and scholarly.

\section{Methodology}

The methodology applied in this research was descriptive as it discusses and describes the various parts of $\mathrm{PhD}$ literature writing process and explains the how to do of them in a very simple and understanding language (Faryadi, 2018). Descriptive analysis is applied to explain the basic features of thesis writing process (García et al., 2015). Descriptive method is very useful in providing basic summaries of the chapters (Al-Raqqad et al., 2017). The followings are the process of $\mathrm{PhD}$ thesis writing process.

\subsection{Types of Literature Review}

1) Primary Literature Review: The articles or documents deal with fresh and original researches that are documented in international journals, conference proceedings and theses. The findings are the result of first hand work. This type of literature is peer reviewed, indexed, and published for the first time.

2) Secondary Literature Review: Deals with specific subjects, books, monographs, and generalization where the information described does not come from the author's own work but is from the work of others that he refers to. It also deals with interpretation and evaluation of original findings, e.g. academic books, journal articles, documentaries, biographies, and annotations. 
3) Tertiary Literature Review: It refers to merged knowledge from primary and secondary sources. It also refers to the summaries, abstracts or annotations of primary and secondary sources. It is rarely used for an academic purpose. Example: encyclopedias, atlases, review articles and so on.

\subsection{Ten Rules of Literature Review}

Rule 1: Identify the topic and audience.

Rule 2: Search and re-search the Literature.

Rule 3: Take notes while reading.

Rule 4: Choose the type of review you wish to write.

Rule 5: Keep the review focused but make it generally interesting.

Rule 6: Be critical and consistent.

Rule 7: Find a logical structure.

Rule 8: Make use of feedback.

Rule 9: Include your own relevant research but be objective.

Rule 10: Be up-to-date, but do not exclude older studies (Marco \& Bourne, 2013).

\subsection{When Evaluating Literature, You Must Ask Yourself}

1) Does the literature review discuss the heart of your problem statement?

2) Does the literature review significantly support your research problem statement?

3) Does the writer agree or disagree with the existing knowledge, and why?

4) Is his/her final judgment or conclusion sound, logical or persuasive?

5) Does the researcher cite literature that proves or disproves his/her problem statement? (Qais, 2012)

\subsection{Advantages of Doing Literature Review}

1) To find the latest studies concerning your topic so that you know who the other researchers are and what they have contributed.

2) To make yourself more knowledgeable in your area of specialization.

3) To answer key questions about your topic of study.

4) To see what methods and methodologies are being used by current researchers so that you can apply them in your own research.

5) To collect supporting evidences to justify the investigation of your problem and hypotheses.

6) To identify any gap in the literature so that your new findings can close or narrow that gap.

\subsection{Objectives of Literature Review}

1) To identify what information is already exists.

2) To identify gap in knowledge.

3) To find out who else is doing the same thing.

4) To identify documented papers about your area of specialization. 
5) To find out what concepts and methodologies are used.

6) To compare and contrast findings and scientific ideas.

7) To identify relationship and designs.

8) To use your solution in case needed.

9) Offer your conclusion and expertise.

\subsection{Literature Review Template}

The literature review format or template varies from one university to another. It is best that you consult your supervisor and your department to make sure you are doing the right thing. However, a typical and general literature review template is as follows:

1) Introduction: Define your topic and the scope of your search. Make a general statement about your research topic before focusing on specific aspects of your research problem. Lastly, determine the scope of your investigation. Mention what type of material you are going to exclude or include.

2) Main Body: Critical evaluation of the literature, use sequential and thematic approaches in your evaluation. Summarize your article reviews critically. Identify the methodology you are going to apply and give proper justification by citing scholarly and peer reviewed papers.

3) Conclusion: Summarize the findings of the selected researchers. Relate their findings to your research topic. Compare scholarly work based on their strengths and weaknesses. Take note of articles that support your claim. Point out the flaws or weaknesses of published work that refute your claim.

4) References: In-text citations. Depending on the type of citation style, all reviewed articles must be acknowledged and must be cited in-text as well as a full citation of the complete source in the reference section.

A Literature Review should help you answer these questions:

1) What scholarly knowledge has been documented on your research topic?

2) Who are these scholars?

3) What theories and hypotheses have been applied by other researchers?

5 ) What type of academic and scholarly questions have been put forward?

6) What methodologies are appropriate for your research?

7) You want to know everything about your topic so that you can write with authority. That's why you need to read up on as many related studies as possible. You need to find the relevant documents, read them carefully and make critical summaries.

\section{Conclusion and Final Checklist for Your Review}

As we have discussed earlier in this chapter, the literature search or review calls for intensive reading of scholarly materials that are relevant to the investigation of your research problem. Reviewing related literature is thus an unavoidable process if you want to find answers to your enquiries as well as seek guidance in the direction of your research. 
Hence, the literature review provides a theoretical and methodological contribution to your sea of knowledge. While the literature review can be a tedious process, it must be conducted in an organized manner, otherwise valuable resources, time, and energy will be wasted.

Remember the following vital points while carrying out your literature review:

1) Before you start writing this chapter, make sure that you know the meaning and the purpose of literature review.

2) Do your literature search based on the objectives and purpose of your study.

3) Did you scrutinize the authentication of the information sources?

4) Do you think your search is judicious?

5) Are the studies cited recent or updated? Did you evaluate the studies critically? Are you concentrating more on primary sources of information?

6) Do you think the study cited is relevant to your research problem?

7) Have you planned how to organize the materials to be read and those that you have read? Have you summarized the important points?

8) Are you satisfied with the new knowledge you have discovered while doing reviews?

9) Do you have enough references to prove or disprove your claims?

10) Were your data correctly analyzed? Do you think your work has made a significant contribution to the existing knowledge?

11) Are you sure you have an answer to your questions? Do you think your work contributed to the knowledge of your peers so that they now know things that they did not know before?

12) Just do your best and then leave it to your examiners to judge your hard work.

\section{Conflicts of Interest}

The author declares no conflicts of interest regarding the publication of this paper.

\section{References}

Al-Raqqad, H. K., Al-Bourini, E. S., Al Talahin, F. M., \& Aranki, R. M. E. (2017). The Impact of School Bullying on Students' Academic Achievement from Teachers Point of View. International Education Studies, 10, 44-50. https://doi.org/10.5539/ies.v10n6p44

Badenhorst, C. (2018). Citation Practices of Postgraduate Students Writing Literature Reviews. London Review of Education, 16, 121-135. https://doi.org/10.18546/LRE.16.1.11

Creswell, J. W. (2005). Educational Research: Planning, Conducting, and Evaluating Quantitative and Qualitative Research. Upper Saddle River, New Jersey.

Dena, T. (2013). The Literature Review: A Few Tips on Conducting It. Health Sciences Writing Centre, University of Toronto.

Faryadi, Q. (2018). PhD Thesis Writing Process: A Systematic Approach-How to Write Your Introduction. Creative Education, 9, 2534-2545.

https://doi.org/10.4236/ce.2018.915192 
Galvan, J. L., \& Galvan, M. C. (2017). Writing Literature Reviews: A Guide for Students of the Social and Behavioral Sciences (3rd Ed.). Glendale, CA: Pyrczak Publishing. https://doi.org/10.4324/9781315229386

García, S., \& Fombona, J. (2015). Approach to the Phenomenon of M-Learning in English Teaching. Digital Education Review, No. 28, 19-36.

Marco, P., \& Bourne, P. E., Editors. (2013). PLoS Comput Biol, 9, PMC3715443.

Price, R. H. (2017). The Four-Part Literature Review Process: Breaking it Down for Students. College Teaching, 65, 88-91.

Qais, F. (2012). How to Write Your PhD Proposal: A Step-by-Step Guide. American International Journal of Contemporary Research, 2, No. 4.

Qais, F. (2017). Everything You Need to Know about PhD Thesis Writing: From Proposal to Viva. Malaysia: Future Expert Solutions.

Rewhorn, S. (2018). Writing Your Successful Literature Review. Journal of Geography in Higher Education, 42, 143-147. 